\title{
Enhancement of subduction/obduction due to hurricane induced mixed layer deepening
}

\author{
Ling Ling Liu ${ }^{a}$, Fan Wang ${ }^{a, *}$ and Rui Xin Huang ${ }^{b}$ \\ ${ }^{a}$ Key Laboratory of Ocean Circulation and Waves, Institute of Oceanology, Chinese \\ Academy of Sciences, Qingdao 266071, China \\ ${ }^{\mathrm{b}}$ Department of Physical Oceanography, Woods Hole Oceanographic Institution, \\ Woods Hole, MA 02543, U.S.A
}

Corresponding author address: Fan Wang, Key Laboratory of Ocean Circulation and Waves, Institute of Oceanology, Chinese Academy of Sciences, Qingdao 266071, China E-mail: fwang@qdio.ac.cn 


\begin{abstract}
Ventilation, including subduction and obduction, in the North Pacific is re-examined, based on SODA outputs and the Eulerian definition. The annual subduction rate averaged from 2001 to 2004 is estimated at $49.8 \mathrm{~Sv}$; while the annual obduction rate is $26.7 \mathrm{~Sv}$.

Furthermore, the annual subduction/obduction rate enhancement induced by tropical cyclones in the North Pacific, defined as the difference between the annual subduction/obduction rate for the cases including the mixed layer depth perturbations induced by tropical cyclones and that for the cases without the perturbations, is estimated. Based on SODA outputs and the mixed layer deepening obtained from a hurricane-ocean coupled model, the annual tropical cyclone-induced subduction rate enhancement averaged from 2001 to 2004 is estimated at $4.4 S v$ and the obduction rate enhancement 5.2Sv; and such enhancement is mainly concentrated in the latitudinal band from $10^{\circ} \mathrm{N}$ to $30^{\circ} \mathrm{N}$.
\end{abstract}




\section{Introduction}

Watermass exchange between the surface layer and the permanent pycnocline below is a key element of the oceanic general circulation and climate. The conception of subduction dates back to Iselin (1939), who first suggested that water is pushed down through the surface layer by Ekman pumping. Stommel (1979) recognized that it is actually the flow leaving the base of a deep winter mixed layer that ventilates the thermocline. This hypothesis is often called the Stommel demon, and it has been followed by a number of ideal-fluid thermocline models and studies of subduction rate diagnosed from the climatological data (e.g., Woods 1985; Huang 1990; Williams 1991; Qiu and Huang 1995; Williams et al. 1995; Marshall 1997).

Most subduction rate diagnostics from both observations (e.g. Qiu and Huang 1995; Karstensen and Quadfasel 2002) and model simulations (e.g. New et al. 1995; Williams et al. 1995; Spall et al. 2000) have been based on the Stommel demon, i.e. treating the mixed layer depth as a snapshot of its late-winter pattern and calculating the ventilation rate in the steady limit. For instance, using a simplified version of the model proposed by Woods (1985) and climatology, Qiu and Huang (1995) estimated the annual subduction rate over the whole North Pacific at $35.2 S v\left(1 S v=10^{6} \mathrm{~m}^{3} \mathrm{~s}^{-1}\right)$ and the obduction rate $7.8 \mathrm{~Sv}$. However, in these studies the effects of climate variability on interannual time scale or shorter was not addressed.

From the definition, the annual subduction/obduction rate is directly associated with the vertical velocity, the variation of mixed layer depth, and the lateral induction of fluid across the sloping base of the mixed layer; thus, the time variability of 
velocity fields and mixed layer depth can both affect its diagnostics. In reality, during some part of the seasonal cycle, the mixed layer is also controlled by small-scale oceanic motions (Pollard and Regier 1992; Follows and Marshall 1994). Marshall (1997) have discussed the possible importance of mesoscale eddies. Hazeleger and Drijfhout (2000) suggested that south of the Gulf Stream extension eddies can enhance the annual subduction rate by almost a factor of two. Qu et al. (2002) estimated the annual subduction rate in the North Pacific at $61.6 \mathrm{~Sv}$, in which the mean flow contributes 49.0 Sv, mesoscale eddies 7.8 Sv, and small-scale eddies 4.6 Sv.

Valdiviseo et al. (2005) has shown that temporal changes of the mixed layer make important contributions to subduction. In reality, there are various perturbations inducing additional temporal changes of the mixed layer depth, which can be induced by different physical processes, such as hurricanes ${ }^{1}$, mesoscale eddies, strong and episodic cooling events associated with anomalous large-scale air-sea interaction on the inter-annual time scale.

Tropical cyclone activity is a vitally important component of the atmospheric circulation system at low- and mid- latitudes. Powerful wind-forcing of tropical cyclones can induce strong turbulent mixing in the upper ocean and entrainment of deep cold water into the mixed layer, resulting in cooling of the mixed layer water, warming below the depth of pre-tropical cyclone mixed layer and deepening of the

\footnotetext{
${ }^{1}$ Hurricane, typhoon, and tropical cyclone have a similar meaning for the issues discussed in this study.
} 
mixed layer (Bender et al., 1993; Emanuel, 2001; Ginis, 2002).

Due to the huge amount of mechanical energy sustaining turbulent motions in the upper ocean during the passage of a tropical cyclone, the mixed layer deepens. As shown in Fig.1, the ocean can be conceptually separated into the mixed layer where density is homogenized by the strong vertical mixing supported by energy from wind stress and the stratified water below the mixed layer. As soon as water enters the mixed layer, it would lose its identity due to the strong vertical mixing. After the passing of a tropical cyclone, the mixed layer retreats, and the stratification in the upper ocean is gradually restored to the pre-hurricane conditions. The restoration of stratification in the upper ocean is a fairly complicated problem and it is a research frontier, as discussed by Price et al. (2008); thus, our discussion here is limited to the kinematical part of the problem only.

It can be readily seen from Fig.1a that during the hurricane-induced deepening phase of the mixed layer, water from the pycnocline enter the mixed layer, leading to obduction; since the transition between these two processes (mixed layer deepening/shoaling) is relatively quick, water entrained into the mixed layer remains close to the location where it leaves the pycnocline. During the second phase, the mixed layer shoals and the upper ocean relaxes back towards the pre-hurricane conditions. Part of water originally sits in the mixed layer is now left behind, i.e. it flows from the mixed layer into the pycnocline. By definition, this corresponds to subduction, as shown in Fig. 1b.

Note that, water entrained into the mixed layer from the pycnocline upstream 
carries its properties from the pycnocline below; thus, it can enhance the communication between the pycnocline and mixed layer. Due to convective mixing water parcels entering the mixed layer quickly lose its identity, such as dissolved oxygen, nutritive salts, chlorophyll etc. The duration of mixed layer deepening associated with hurricane is relatively short; the mixed layer shoaling and stratification restoration ensure, and water is detrained through the base of the mixed layer and re-enters the pycnocline downstream. Thus, there is a quick switching between the obduction phase and subduction phase. The subducted water can carry its physical and chemical properties determined by the mixed layer processes, and these properties are essentially conserved during and after subduction.

As discussed by Qiu and Huang (1995), in the ocean there are ambiductive regions where both subduction and obduction take place and compensate for each other. In a similar way, tropical cyclones can induce mixed layer deepening through mechanical stirring; thus, they may enhance local obduction rate and subduction rate, thus giving rise to ambiduction. Such ambiduction may play important roles in regulating the oceanic circulation and ecosystem.

Recent study (Jansen et al., 2010) has shown that due to the mixed layer deepening in the following winter, only about one quarter of the heat that is mixed download by tropical cyclones eventually makes it into the permanent pycnocline, and the other would be reabsorbed by the mixed layer and lost to the atmosphere. Similarly, mixed layer deepening induced by tropical cyclones cannot be simply regarded as the subduction/obduction rate enhancement induced by tropical cyclones 
at the given station; water entrained into the mixed layer during the passage of tropical cyclones may be originated from the seasonal pycnocline, rather than the permanent pycnocline; similarly, water parcels released during the mixed layer retreating period may be re-entrained into the mixed layer downstream. Therefore, the calculation of subduction/obduction rate enhancement induced by tropical cyclones must be carried out by following the exact definition of subduction/obduction.

In this study, we will be focused on annual subduction/obduction rate enhancement (averaged over the time period from 2001 to 2004) induced by tropical cyclones in the North Pacific. The data used in this study include SODA outputs and the mixed layer deepening obtained from a hurricane-ocean coupled model.

This paper is organized as follows. In Section 2, we simply introduce the SODA outputs and the mixed layer deepening induced by tropical cyclones obtained from a hurricane-ocean coupled model. The subduction/obduction rate for the cases including mixed layer depth perturbations induced by tropical cyclones at a given station is discussed in Section 3. The annual subduction/obduction rate enhancement induced by tropical cyclones in the North Pacific is estimated in Section 4. Finally, we conclude in Section 5.

\section{The datasets}

\section{a. SODA outputs}

There are several versions of SODA (Carton et al., 2005), depending on the experiment setup. Version SODA2.0.2 is forced by ERA-40 wind stresses, and 
assimilated all available data from hydrographic stations, XBTs, and floats, but does not use satellite altimetry; this dataset is available for the time period 1958-2001. SODA2.0.4 uses a merged product of QuickSCAT and the NCEP/NCAR reanalysis, extends SODA2.0.2 from 2002 to 2007.

The monthly mean temperature, salinity and velocity fields of SODA2.0.2 (2000-2001) and SODA2.0.4 (2002-2005) are used in our calculation, which are mapped onto a $0.5^{\circ} \times 0.5^{\circ}$ horizontal grid with 40 levels. The mixed layer depth is defined as the depth at which $\sigma_{\theta}$ (potential density) is $0.125\left(\mathrm{~kg} / \mathrm{m}^{3}\right)$ greater than its value at the sea surface. The horizontal velocities taken from SODA are directly used in this study. Vertical velocity in our calculation is diagnosed from the divergence/convergence of the SODA horizontal velocity; thus, it is quite noisy, especially near the boundary. To overcome problems associated with such noisy vertical velocity field, we first smooth the vertical velocity diagnosed from SODA outputs (weighting 1-2-1 in zonal and meridional, respectively), and then set an upper limit of $3.2 \times 10^{-6} \mathrm{~m} / \mathrm{s}(100 \mathrm{~m} / \mathrm{yr})$. This choice of vertical velocity upper limit is based on the physical reasoning that the contribution of vertical pumping is not larger than 100m/yr according to Qiu and Huang (1995).

\section{b. The mixed layer deepening induced by tropical cyclones}

The mixed layer deepening induced by tropical cyclones is obtained from a coupled hurricane-ocean model, which consists of two independently developed and tested models, that is, the axisymmetric hurricane model of Emanuel (1989) and the 
reduced gravity ocean model of Cooper and Thompson (1989). The formulation of both models has been described in detail in the cited references; the principle physical processes, the balances, and the coupling procedure were described by Schade and Emanuel (1999) and Liu et al. (2008). There are three layers in the ocean model: a well-mixed layer on the top, a strongly stratified layer in the middle, and a deep and stagnant abyssal layer on the bottom. Momentum is turbulently exchanged through the air-sea interface. The atmospheric component of the coupled model is axisymmetric in gradient wind and hydrostatic balance and consists of three layers: a boundary layer and two tropospheric layers. On the whole, the ocean model is forced by the surface wind field constructed from the axisymmetric flow in the hurricane model plus the translation velocity of the hurricane. In turn, the hurricane model is forced by an axisymmetric SST field constructed through azimuthal averaging of the SST field around the center of the hurricane obtained from the ocean model.

Using the hurricane-ocean coupled model, we calculated the mixed layer deepening induced by over 140 tropical cyclones from 2001 to 2004 in the North Pacific. The mixed layer deepening for an individual tropical cyclone is defined as the difference between the mixed layer depth before the arriving of a tropical cyclone and the maximal mixed layer depth obtained from the coupled model at a given station during the passage of the tropical cyclone. The distribution of the total mixed layer deepening averaged from 2001 to 2004 is shown in Fig. 2. As well known, there is a possibility that several tropical cyclones can pass through the same grid point within one year. In order to understand how much water is entrained into the mixed layer by 
tropical cyclones, this figure shows the accumulated mixed layer deepening, that is, if there are $\mathrm{N}$ tropical cyclones passing through a given station in one year and each time the mixed layer deepening is denoted as $d h_{j}$, then the total annual mixed layer deepening induced by tropical cyclones at this station is defined as the sum of these individual cyclones, i.e. $d H=\sum_{j=1}^{N} d h_{j}$. It is readily seen that mixed layer deepening induced by tropical cyclones are mostly confined in the latitudinal band from $10^{\circ} \mathrm{N}$ to $30^{\circ} \mathrm{N}$.

The mixed layer deepening associated with tropical cyclone is directly linked to water mass exchange through the base of the mixed layer. Thus, it can affect the annual mean obduction/subduction, and the accurate calculation is described in the following section.

\section{Subduction/obduction rate for the cases including mixed layer depth perturbations at a given station}

Owing to the strong wind associated with the tropical cyclones, large amount of mechanical energy can induce strong mixing in the upper ocean, leading to deepening of the mixed layer. After the passing of the tropical cyclone, the mixed layer gradually restores to the initial state with a typical e-folding time scale of 5-20 days (Nelson, 1998; Price et al., 2008). For simplicity, we assume that perturbation of mixed layer depth induced by a tropical cyclone at a given station is in the following form:

$$
h_{T c}=d h \cdot \sin \left(\left(t-t_{T c}+\Delta T / 2\right) \cdot \pi / \Delta T\right), t_{T c}-\Delta T / 2 \leq t \leq t_{T c}+\Delta T / 2,
$$

where $h_{T c}$ is the mixed layer depth perturbation induced by the tropical cyclone, $d h$ 
is the amplitude of mixed layer deepening at the given station, $t_{T c}$ is the arriving time of the tropical cyclone, and $\Delta T$ the duration of the perturbation.

As an example, the annual evolution of mixed layer depth at the station $\left(153.75^{\circ} \mathrm{E}, 16.75^{\circ} \mathrm{N}\right)$, including the perturbations due to the passing tropical cyclones is shown in Fig. 3, where the background seasonal cycle is taken from SODA outputs in 2001, and there are two perturbations induced by tropical cyclones, that is, in this year two tropical cyclones affect this station. The amplitude of the first perturbation is $115.2 \mathrm{~m}$ and the occurring time is $287^{\text {th }}$ day according to the results from the coupled model; while the amplitude of the second perturbation is $12.4 \mathrm{~m}$ and the occurring time is $343^{\text {rd }}$ day. In addition, the duration of the perturbations is set as $\Delta T=14$ days .

Mixed layer depth perturbations induced by tropical cyclones are mostly confined in the latitudinal band from $10^{\circ} \mathrm{N}$ to $30^{\circ} \mathrm{N}$, where the mixed layer typically reaches the maximum in late winter, with the amplitude of seasonal variation on the order of $20-120 \mathrm{~m}$. Furthermore, due to the activity of the tropical cyclones, the amplitude of additional mixed layer perturbation in the North Pacific is on the order of $100 \mathrm{~m}$ (Liu et al. 2008), which is of the same order as the amplitude of seasonal variation of the mixed layer depth. The large-amplitude perturbations associated with tropical cyclones can produce rapid and larger amplitude mixed layer deepening/shoaling, thus alternating the subduction/obduction rate at a given station. Our discussion will be focused on the case when the tropical cyclone passes the station where the subduction/obduction rate is calculated.

In the western North Pacific, the tropical cyclone usually moves northwestward, 
with a relatively fast speed, on the order of a few meters per second. On the other hand, in the corresponding latitudinal band, the subducted water moves southwestward, with a relatively slow speed, on the order of centimeters per second. These two types of trajectories cross each other, and the effect of a tropical cyclone can be treated as an isolated perturbation that lasts only a short time. Thus, the stations along the water parcel trajectories downstream can be considered as uninfluenced by the tropical cyclone. That is, the role of the tropical cyclone can be considered as an event confined to a relatively narrow vicinity of space and time along the water parcel trajectory in the calculation of subduction. Similar argument also applies to the calculation of obduction.

\section{a. The annual subduction rate}

We start with the definition of the instantaneous detrainment rate (e.g., De Szoeke 1980; Cushman-Roisin 1987)

$$
D=-\left(w_{m b}+\mathbf{u}_{m b} \cdot \nabla h_{m}+\frac{\partial h_{m}}{\partial t}\right),
$$

where the subscript $m b$ denotes the mixed layer base, $w_{m b}$ and $\mathbf{u}_{m b}$ are the vertical and horizontal velocities at the base of mixed layer, and $h_{m}$ the depth of mixed layer. Since only effective detrainment contributes to subduction, the annual subduction rate in Eulerian coordinates can be defined as the accumulation of the effective detrainment in one year:

$$
S_{E}=\frac{1}{T} \int_{T_{s}^{e d}}^{T_{e}^{e d}} D d t
$$

where $\mathrm{T}=1$ year, $T_{s}^{e d}$ and $T_{e}^{e d}$ are times when effective detrainment starts and ends, 
which are determined by tracing trajectories of water parcels (released at the base of mixed layer) downstream for one year. If the water is re-taken by the rapid mixed layer deepening downstream, the detrainment is ineffective. Only if the water parcels finally enter the permanent pycnocline, the detrainment is considered effective, and thus contributes to subduction.

However, the Lagrangian definition requires a careful scrutiny for the cases including a large-amplitude perturbation. In Lagrangian coordinates, the annual subduction rate is defined along the first effective subducted trajectory (Qiu and Huang, 1995):

$$
S_{L}=-\bar{w}_{t r}+\frac{1}{T}\left(h_{m, 0}-h_{m, 1}\right)
$$

where $\bar{w}_{t r}$ is the vertical velocity averaged over the one-year trajectory, $h_{m, 0}$ and $h_{m, 1}$ denote the mixed layer depths along the first effective trajectory at the beginning and ending time, respectively. Although using the first effective trajectory is a convenient choice and it works in the normal cases, close scrutiny reveals, however, such a choice may not be able to reflect the contribution of tropical cyclones. No matter how large is the tropical cyclone-induced perturbation in the mixed layer depth, the annual subduction rate calculated by this approach remains the same. Thus, the traditional Lagrangian definition is not suitable in studying the contribution to subduction induced by large amplitude perturbations in the mixed layer depth associated with tropical cyclones. It seems clear that if the Lagrangian coordinate is used to study the subduction induced by tropical cyclones, new definitions must be introduced. Thus, in the present study, the Eulerian definition will be used. 
As an example, subduction rate based on Eulerian definition is calculated at a given station $\left(153.75^{\circ} \mathrm{E}, 16.75^{\circ} \mathrm{N}\right)$. The mixed layer depth consists of two terms, the regular seasonal cycle and the tropical cyclone-induced perturbations, which is set as shown in Fig. 3. Moreover, the regular mixed layer depth and the vertical and horizontal velocities in the upper ocean are directly taken from SODA outputs in year 2001.

We calculate the annual subduction rate for both the cases with and without the mixed layer depth perturbations, Table 1 . It is readily seen that the perturbations of mixed layer depth add on $49.5 \mathrm{~m} / \mathrm{yr}$ to the annual subduction rate. More interestingly, there are two windows of effective detrainment, as shown in Fig.4. For the cases without the perturbations induced by tropical cyclones, the duration of effective detrainment is 33 days from March to April, with a small contribution each day (Fig.4a). However, for the case including the effect of tropical cyclones, there is additionally a second window of effective detrainment corresponding to the multi-peak phenomenon in the variation of the mixed layer depth. The additional new window is rather narrow due to the rapid passing of the first tropical cyclone; however, the daily contribution within the second window is much larger, Fig.4b. On the other hand, it is readily seen that the perturbations induced by the second tropical cyclone at the end of 2001 have no effect on the local subduction rate.

To understand how the perturbations can contribute to the annual subduction rate, we carried out some additional analysis about the annual subduction rate at the given station $\left(153.75^{\circ} \mathrm{E}, 16.75^{\circ} \mathrm{N}\right)$, with the normal subduction rate of $40.8 \mathrm{~m} / \mathrm{yr}$, Table1. 
The first perturbation shown in Fig.3 was used as an example to study the sensitivity to the amplitude of perturbation (a), the occurring time of perturbation (b), and the duration of perturbation (c) (Fig.5). It is readily seen that for the case including small amplitude perturbations (small maximal mixed layer deepening induced by tropical cyclone), the perturbations have no effect on the annual subduction rate. However, if the amplitude of perturbations is larger than a critical value $(50.8 \mathrm{~m}$ for the present case), the annual subduction rate is enhanced rapidly with the increase of the perturbation amplitude, Fig. 5a. In Eulerian coordinates, the enhancement of subduction rate is insensitive to the occurring time of perturbation from September to October, Fig.5b. On the other hand, for the present case the annual subduction rate is a little sensitive to the duration of perturbation, Fig. 5c.

\section{b. The annual obduction rate}

The annual obduction rate for the cases including mixed layer depth perturbations can be defined in a way very similar to the annual subduction rate. First, it can be defined in Eulerian coordinates,

$$
O_{E}=-\frac{1}{T} \int_{T_{e}^{e e}}^{T_{s}^{e e}} D d t
$$

where $T_{s}^{e e}$ and $T_{e}^{e e}$ are the starting and ending times of effective entrainment in one year.

In the same way, the traditional Lagrangian definition based on the last effective obducted trajectory cannot reflect the effect of perturbation induced by tropical cyclones. Thus, the following discussion about obduction rate for the cases including 
perturbations will be based on the Eulerian definition.

As an example, we used the same cases above for the calculation of subduction enhancement induced by mixed layer depth perturbation. Note that without perturbations in the mixed layer, the annual obduction rate is zero for the present case as it is true for the interior of a subtropical gyre interior. The sensitivity of the annual obduction rate is as follows: (d) with various amplitude of perturbation; (e) with different arriving time of the tropical cyclone; (f) with different duration of perturbation, Fig. 5. If the amplitude of the mixed layer perturbation is smaller than a critical value, the annual obduction rate remains zero. When the perturbation amplitude is larger than the critical value (62.9m for the given station), the annual obduction rate would increase with the enhancement of the mixed layer perturbation amplitude.

Furthermore, for the present example the enhancement of obduction rate is sensitive to the occurring time of perturbation, Fig.5e. In addition, the annual obduction rate is insensitive to the duration of perturbation, Fig. $5 f$.

It is worthwhile to note that there are many factors which can affect the subduction/obduction rate induced by tropical cyclones, such as the seasonal cycle of mixed layer depth at the given station, the three-dimensional structure (u, v, w, mixed layer depth) in the ocean, the amplitude, occurring time and duration of perturbation induced by tropical cyclones. It is rather complex, and the above results was only for the given station $\left(153.75^{\circ} \mathrm{E}, 16.75^{\circ} \mathrm{N}\right)$ in the year 2001 . If the perturbation was applied to another station, the result may be different. 


\section{Enhancement of subduction/obduction rate induced by tropical cyclones in the}

\section{North Pacific}

Tropical cyclones constitute a critical component of climate system and they vary greatly in their location and strength; thus, the subduction/obduction rate enhancement induced by an individual tropical cyclone at a given station may not be representative for their contribution to the basin-scale ventilation rate. Each year, there are many tropical cyclones; thus, a more objective approach is to estimate the accumulated contribution from these tropical cyclones. Our focus in the following discussion is the total contribution of tropical cyclones to the basin-integrated subduction/obduction rate.

Here, we estimate the annual subduction/obduction rate enhancement induced by tropical cyclones in the North Pacific averaged over years 2001 to 2004, which is defined as:

$$
\begin{aligned}
& S_{T c}=S_{\text {tot }}-S_{\text {NoTc }}, \\
& O_{T c}=O_{\text {tot }}-O_{\text {NoTc }},
\end{aligned}
$$

where $S_{T c} / O_{T c}$ is the subduction/obduction rate enhancement induced by tropical cyclones; $S_{\text {tot }} / O_{\text {tot }}$ is the annual subduction/obduction rate for the cases including the perturbations induced by tropical cyclones and $S_{\text {NoTC }} / O_{\text {NoTC }}$ for the cases without the perturbations. In order to identify the roles of tropical cyclones, the annual subduction/obduction rate for the cases with and without the perturbations induced by tropical cyclones are both calculated using the Eulerian definition. 
a. Subduction/obduction rate in the North Pacific from SODA outputs without tropical-cyclone induced perturbations

We begin with calculating the subduction/obduction rate from SODA outputs only and without tropical-cyclone induced perturbations. According to the Eulerian definition, we should first determine the time period of effective detrainment/entrainment; however, the monthly datasets was too sparse to accurately capture the starting and ending time of effective detrainment/entrainment in one year. Thus, the daily mean data obtained by linear interpolation, replacing the original SODA outputs, was used to examine the annual subduction/obduction rate in the North Pacific in this study. For a given station, water parcels are released/received once per day and the corresponding one-year trajectory forward/backward in space and time are traced with a regular interval of two days to ascertain whether it is effective. The total annual accumulation of subduction (obduction) at a given station is calculated by summing up the daily effective detrainment (entrainment) at this station. Any trajectory which intersects the mixed layer downstream/upstream during the corresponding one-year period is defined as ineffective and the contribution associated with the corresponding starting (ending) day of such a trajectory is set to be zero.

The distribution of the annual subduction rate in the North Pacific averaged from 2001 to 2004 is shown in the upper panel in Fig. 6. It is readily seen that subduction mainly takes place in the subtropical basin, and the pattern of subduction rate are essentially similar to that of Qiu and Huang (1995), which was calculated from 
Levitus (1982) climatological data according to the Lagrangian definition. However, the total volume flux from the mixed layer to permanent pycnocline integrated over the whole North Pacific is estimated at the value of $49.8 \mathrm{~Sv}$, which is much larger than Qiu and Huang's result of 35.2 Sv.

The large difference between our result and Qiu and Huang's result may be attributed to the following factors: (1) the difference between Eulerian and Lagrangian definitions; (2) the difference between the dataset generated through data simulation and the climatological dataset based on hydrographic observations; (3) the difference between the velocity obtained from a numerical model and the velocity inferred from hydrographic data and based on the dynamical calculation using a reference level; (4) the difference between the mean obtained by averaging over different years in our current calculation and the climatological calculation, as reported by Qiu and Huang (1995), due to the nonlinearity rectification (Trossman et al., 2009; Liu and Huang, 2011) . These factors are discussed in detail in a separated paper (Liu and Huang, 2011); thus, we do not address this issue in this study. However, it is worthwhile to note that the validity of SODA outputs in calculating ventilation rate has been proved by Liu and Huang (2011). According to their result, based on Lagrangian definition, the subduction rate using the climatologically mean SODA is similar to Qiu and Huang's (1995) result; in addition, the subduction rate based on SODA outputs year-by-year is similar to that from OFES (Qu and Chen, 2009). Therefore, it can be concluded that such datasets can be used to analysis the subduction rate.

Similarly, the annual obduction rate, shown in the lower panel in Fig.6, is similar 
to the result from the Lagrangian definition, which mainly takes place in the subpolar basin and the intergyre boundary. And the annual obduction rate in the North Pacific averaged from 2001 to 2004 is $26.7 \mathrm{~Sv}$.

b. The subduction/obduction rate enhancement induced by tropical cyclones in the North Pacific

We now turn to the calculation of the annual subduction/obduction rate in the North Pacific for the case including mixed layer depth perturbations induced by tropical cyclones. In this case, the mixed layer depth perturbations induced by tropical cyclones will be added to the daily-mean mixed layer depth obtained by linear interpolation from SODA outputs. It is well known that there is a possibility that several tropical cyclones can pass through the same grid point within one year, in this calculation each perturbation induced by a tropical cyclone should be added to the background daily-mean mixed layer depth from SODA, as shown for the station $\left(153.75^{\circ} \mathrm{E}, 16.75^{\circ} \mathrm{N}\right)$ in Fig.3.

The mixed layer depth perturbation induced by a tropical cyclone at a given station is idealized as a simple sinusoidal function of time, Eq. (2), as discussed above. As discussed in previous studies, after the passing of a tropical cyclone, the wake left behind in the ocean would relax back to the pre-hurricane state over the time period of 5-20 days (Nelson, 1998; Price et al., 2008). Therefore, for simplicity the duration of the perturbation is set at 14 days.

Based on these settings, the annual subduction/obduction rate for the cases 
including the tropical cyclone-induced perturbations is calculated, and then the subduction/obduction rate enhancement induced by tropical cyclones is calculated according to Eq. (7).

The annual subduction rate enhancement induced by tropical cyclones in the North Pacific averaged from 2001 to 2004 is shown in Fig. 7 (upper panel) and the total subduction rate enhancement is estimated at $4.4 \mathrm{~Sv}$. Although the subduction rate enhancement induced by tropical cyclones is only $8.8 \%$ of that based on the smoothed monthly mean data, most of this subduction is concentrated within the latitudinal band from $10^{\circ} \mathrm{N}$ to $30^{\circ} \mathrm{N}$, consistent with the spatial distribution of the mixed layer deepening.

The effect of the tropical cyclones on the subduction rate can be divided into two cases, as shown in the upper panel in Fig.7. The first is that the perturbation induced by tropical cyclones can increase the annual subduction rate at the stations the tropical cyclones pass through. However, for the stations around the regions where tropical cyclones occur, the forward trajectories may be intersected by the additional perturbation induced by tropical cyclones, and then the time period of effective detrainment may be cut down, the corresponding subduction rate at the this station could decrease.

The lower panel in Fig.7 shows the distribution of the annual subduction rate for the cases including the tropical cyclone-induced perturbations averaged from 2001 to 2004. The left is the meridional distribution of the zonal integrated results, where the black line is the subduction rate for the cases without the perturbations and the red 
line is that for the cases with the perturbations. From the meridional distribution, it is readily seen that tropical cyclones greatly enhance the annual subduction rate in the $10^{\circ}-30^{\circ} \mathrm{N}$ latitudinal band.

Similar situations appear in the distribution of the annual obduction rate, Fig. 8. The total obduction rate enhancement induced by tropical cyclones is estimated at 5.2 Sv, $19.5 \%$ of the obduction rate based on the smooth monthly mean data. And in the same way, the effect of tropical cyclones to obduction rate can be divided into two cases. First, it may increase the local obduction rate. Second, for the stations from which the trajectories (used to check whether it originates from the permanent pycnocline) are intersected by the perturbations induced by tropical cyclones, the annual obduction rate can be reduced.

Although the annual subduction/obduction rate enhancement induced by tropical cyclones are much smaller than that based on the monthly mean data, it may play a quite important role in many aspects of marine environment. Since stratification in tropic ocean is strong and the hurricane-induced subduction/obduction enhancement occur mainly in summer and autumn, tropical cyclones may play an important role in the oceanic general circulation and climate. Furthermore, tropical cyclones induced subduction/obduction enhancement may have important role in the transfer of carbon dioxide and other tracers between the upper ocean and pycnocline.

\section{Conclusion}

Subduction/obduction is a key index for the study of oceanic general circulation 
and climate. In this study, ventilation in the North Pacific is re-examined using the Eulerian definition and SODA outputs. Averaged over the period of 2001 to 2004, the annual subduction rate in the North Pacific, which mainly takes place in the subtropical basin, is $49.8 \mathrm{~Sv}$; the annual obduction rate, which mainly occurs in the subpolar basin and the region near the inter-gyre boundary, is $26.7 \mathrm{~Sv}$.

The annual subduction/obduction rate enhancement induced by tropical cyclones in the North Pacific is estimated based on SODA outputs and the mixed layer deepening obtained from a hurricane-ocean coupled model. Averaged over the period of 2001 to 2004, the annual subduction rate enhancement is $4.4 S v$ and the obduction rate enhancement is $5.2 \mathrm{~Sv}$, and such enhancement is mostly confined to the latitudinal band from $10^{\circ} \mathrm{N}$ to $30^{\circ} \mathrm{N}$ in the Western Pacific.

Our study is only the first step toward unraveling the complicated roles of tropical cyclones in the oceanic ventilation. There are several factors which may induce errors. First of all, the time scale of restoration of stratification is most certainly variable from case to case (Price et al., 2008); however, in the present study the duration of perturbations induced by all tropical cyclones are assumed to be 14 days; such a simplification may induce errors. Second, only the effect of mixed layer depth perturbation induced by tropical cyclones has been examined in our study, but other dynamical effects have been omitted for simplicity. For example, it is well known that the wind stress associated with the tropical cyclones can induce Ekman upwelling near the center of typhoon and downwelling away from typhoon's core. As a result, tropical cyclones can alter the vertical velocity along the primary trajectory in 
the vicinity of the tropical cyclone's pathway, and thus affect the annual subduction/obduction rate. The complicated dynamical effects of tropical cyclones omitted in the present study should be examined in further study. Third, the data-processing, such as, the usage of model vertical velocities, and the pre-processing processes performed to derive the SODA datasets, may induce large errors. It is difficult to quantify the errors associated with above processes; however, the errors in our estimated subduction and obduction rates could be on the order of $10 \%$.

In addition, several recent studies have focused on the important role of TC stirring in the global heat budgets of past climates (Emanuel, 2002; Korty et al., 2008; Jansen and Ferrari, 2009; Fedorov et al., 2010; Jansen et al., 2010), the ocean-atmosphere CO2 exchange (Bates et al., 1998) and its biological effect (Babin et al., 2004). However, the impact of subduction/obduction enhancement induced by tropical cyclones to the oceanic general circulation remains unclear at the present time. For example, tropical cyclones are active in late summer and autumn, and the annual subduction/obduction take place mostly in late winter. A natural question is then, how does the subduction/obduction enhancement induced by tropical cyclones affect the oceanic general circulation? To answer these questions further study is clearly needed and we hope this study will stimulate interest in exploring the contribution of tropical cyclones in the oceanic general circulation and climate. 


\section{Acknowledgments}

We thank three reviewers for their insightful suggestions and comments. This study is supported by National Natural Science Foundation of China under Grant 40906007 and 40890150. 


\section{References}

Babin, S. M., J. A. Carton, T. D. Dickey, and J. D. Wiggert, 2004. Satellite evidence of hurricane-induced phytoplankton blooms in an oceanic desert. J. Geophys. Res., 109, C03043, doi: 10.1029/2003JC001938.

Bates, N. R., A. H. Knap, and A. F. Michaels, 1998. Contribution of hurricanes to local and global estimates air-sea exchange of CO2. Nature, 395, 58-61.

Bender, M. A., I. Ginis and Y. Kurihara, 1993. Numerical simulations of tropical cyclone-ocean interaction with a high-resolution coupled model. J. Geophys. Res., 98, 23245-23262.

Carton, J. A., B. S. Giese, and S. A. Grodsky, 2005. Sea level rise and the warming of the oceans in the SODA ocean reanalysis. J. Geophys. Res., 110, C09006, doi: 10.1029/2004JC002817.

Cooper, C., and J. D. Thompson, 1989. Hurricane-generated currents on the outer continental shelf. Part I: Model formulation and verification. J. Geophys. Res., 94, 12513-12539.

Cushman-Roisin, B., 1987: Subduction. Dynamics of the Oceanic Surface Mixed Layer. P. Muller and D. Henderson, Eds., Hawaii Inst. Of Geophysics Special Publications, 181-196.

De Szoeke, R. A., 1980: On the effects of horizontal variability of wind stress on the dynamics of the ocean mixed layer. J. Phys. Oceanogr., 10, 1439-1454.

Emanuel, K. A., 1989. The finite amplitude nature of tropical cyclogenesis. J. Atmos. Sci., 46, 3431-3456. 
-----, 2001. Contribution of tropical cyclones to meridional heat transport by the oceans. J. Geophys. Res., 106, 14771-14781.

-----, 2002. A simple model of multiple climate regimes, J. Geophys. Res., 107 (D9), doi: 10.1029/2001JD001002.

Fedorov, A. V., C. Brierley, and K. Emanuel, 2010. Tropical cyclones and permanent El Nino in the early Pliocene epoch. Nature, 463, 1066-1070.

Follows, M. J., and J. C. Marshall, 1994. Eddy driven exchange at ocean fronts. Ocean Modell., 102, 5-9.

Ginis, I., 2002. Hurricane-ocean interactions, Tropical cyclone-ocean interactions, chapter 3. In Atmosphere-Ocean Interactions, edited by Perrie W, WIT press. Advances in Fluid Mechanics Series 33, 83-114.

Hazeleger, W., and S. S. Drijfhout, 2000. Eddy subduction in a model of the subtropical gyre. J. Phys. Oceanogr., 30, 677-695.

Huang, R. X., 1990. On the three-dimensional structure of the wind-driven circulation in the North Atlantic. Dynamics of Atmospheres and Oceans, 15, 117--159.

Iselin, C. O. D., 1939. The influence of vertical and lateral turbulence on the characteristics of the waters at mid-depths. Trans. Amer. Geophys. Union, 20, 414-417.

Jasen, M., and R. Ferrari, 2009. Impact of the latitudinal distribution of tropical cyclones on ocean heat transport. Geophys. Res. Lett., 36, L06604, doi: 10.1029/2008GL036796.

-----, -----, and T. A. Mooring, 2010. Seasonal versus permanent thermocline warming 
by tropical cyclones. Geophys. Res. Lett., 37, L03602, doi: 10.1029/200GL041808.

Karstensen, J., and D. Quadfasel, 2002. On the formation of the Southern Hemisphere and thermocline waters: Water mass conversion and subduction. J. Phys. Oceanogr., 32, 3020-3038.

Korty, R. L., K. A. Emanuel, and J. R. Scott, 2008. Tropical cyclone-induced upper ocean mixing and climate: Application to equable climates. J. Clim., 21, 638-654.

Levitus, S., 1982. Climatological Atlas of the World Ocean. NOAA Prof. Paper NO.13, U.S. Govt. Printing Office, Washington, DC, 173pp.

Liu, L. L., W. Wang and R. X. Huang, 2008. The mechanical energy input to the ocean induced by tropical cyclones. J. Phys. Oceanogr., 38, 1253-1266.

------, R. X. Huang, 2011. The global subduction/obduction rates, their interannual and decadal variability. Submitted.

Marshall, D., 1997. Subduction of water masses in an eddying ocean. J. Mar. Res., 55, 201-222.

Nelson, N. B., 1998. Spatial and temporal extent of sea surface temperature modifications by hurricanes in the Sargasso Sea during the 1995 season. Mon. Weather Rev., 126, 1364-1368.

New, A. L., R. Bleck, Y. Jia, R. Marsh, M. Huddleston, and S. Barnard, 1995. An isopycnic model study of the North Atlantic. Part I: Model experiment. J. Phys. Oceanogr., 25, 2667-2699. 
Pollard, R. T., and L. A. Regier, 1992. Vorticity and vertical circulation at an ocean front. J. Phys. Oceanogr., 22, 609-625.

Price, J. F., J. Morzel, and P. P. Niiler, 2008: Warming of SST in the cool wake of a moving hurricane. J. Geophys. Res., 113, C07010, doi: 10.1029/2007JC004393.

Qiu, B., and R. X. Huang, 1995. Ventilation of the North Atlantic and North Pacific: Subduction versus obduction. J. Phys. Oceanogr., 25, 2374-2390.

Qu, T., S.-P. Xie, H. Mitsudera, and A. Ishida, 2002. Subduction of the North Pacific mode waters in a global high-resolution GCM. J. Phys. Oceanogr., 32, 746-763.

Schade, L. R., and K. A. Emanuel, 1999: The ocean's effect on the intensity of tropical cyclones: Results from a simple Coupled Atmosphere-Ocean Model. $J$. Atmos. Sci., 56, 642-651.

Spall, M. A., R. A. Weller, and P. W. Furey, 2000. Modeling the three-dimensional upper ocean heat budget and subduction rate during the Subduction Experiment. J. Geophys. Res., 103, 15817-15831.

Stommel, H. M., 1979. Determination of water mass properties of water pumped down from the Ekman layer to the geostrophic flow below. Proc. Natl. Acad. Sci., USA, 76, 3051-3055.

Valdivieso da Costa, M., H. Mercier, and A. M. Treguier, 2005. Effects of the mixed layer time variability on kinematic subduction rate diagnostics. J. Phys. Oceanogr., 35, 427-443.

Williams, R. G., 1991. The role of the mixed layer in setting the potential vorticity of the main thermocline. J. Phys. Oceanogr., 21, 1803-1814. 
-----, M. A. Spall, and J. C. Marshall, 1995. Does Stommel’s mixed-layer “demon” work? J. Phys. Oceanogr., 25, 3089-3102.

Woods, J. D., 1985. The physics of pycnocline ventilation. Coupled Ocean-Atmosphere Models. J. C. J. Nihoul, Ed., Elsevier Sci. Pub., 543-590. 